04

\title{
Взаимодействие ударной волны со свободным тлеющим разрядом
}

(C) А.С. Барышников, И.В. Басаргин, С.В. Бобашев, Н.А. Монахов, П.А. Попов, В.А. Сахаров

Физико-технический институт им. А.Ф. Иоффе РАН, Санкт-Петербург

๑ E-mail: v.sakharov@mail.ioffe.ru

Поступило в Редакцию 14 июля 2016 г.

Двойным электрическим зондом проведены измерения распределения заряженных частиц в плазме тлеющего разряда при прохождении через нее ударной волны. Установлено, что уменьшение концентрации ионов перед фронтом ударной волны связано с возникновением ионно-звуковых колебаний в плазме.

DOI: 10.21883/PJTF.2017.11.44692.16407

Интерес к проблеме взаимодействия ударной волны с плазмой газового разряда имеет давнюю историю [1-3]. Основное внимание уделялось изучению структуры ударной волны в плазме тлеющего разряда и, в частности, влиянию электронов на ширину фронта ударной волны. В работах [2,3] отмечалось изменение проводимости плазмы перед ударной волной, однако в силу различных причин должного внимания изучению этого эффекта не уделялось. В работах последнего времени $[4,5]$ было подтверждено уменьшение концентрации заряженных частиц перед фронтом ударной волны и показано, что это изменение происходит одновременно во всем объеме разряда. Данная работа является продолжением начатых исследований, направленных на изучение физического механизма наблюдаемого явления.

Работа проводилась на экспериментальной установке, состоящей из цилиндрической камеры диаметром $300 \mathrm{~mm}$ и высотой $400 \mathrm{~mm} \mathrm{c}$ парой конических электродов, расположенных вертикально вдоль ее оси на расстоянии $100 \mathrm{~mm}$ друг от друга. Между электродами зажигался стационарный тлеющий разряд, видимая часть которого имеет вид тела вращения с увеличивающимся кверху поперечным сечением. Давление в камере поддерживалось равным $4 \mathrm{kPa}$. 


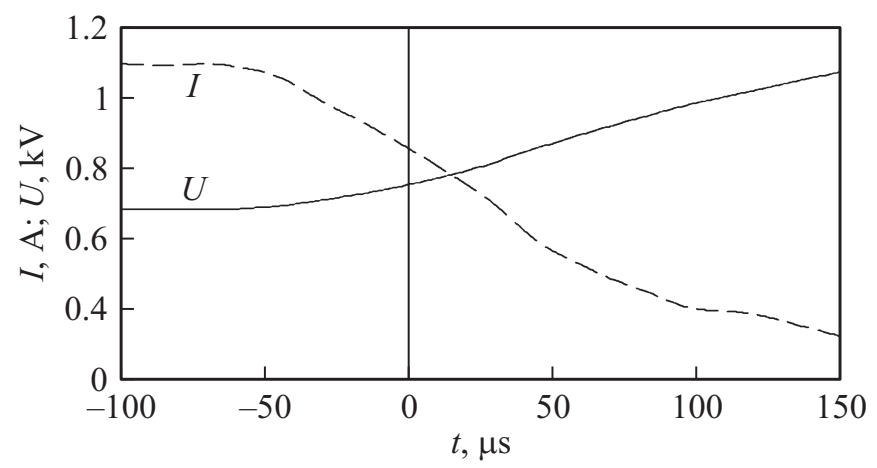

Рис. 1. Изменение тока разряда $I$ и напряжения $U$ на разрядном промежутке при взаимодействии ударной волны с газовым разрядом.

Радиус поперечного сечения разряда, на котором концентрация электронов уменьшается на порядок относительно значения в центре, составляет примерно $40 \mathrm{~mm}$, что соответствует $1 / 4$ радиуса рабочей камеры. В центре разряда температура нейтральной компоненты составляет $\sim 1300 \mathrm{~K}$, электронов $\sim 12000 \mathrm{~K}$, степень ионизации не более $10^{-6}$. В направлении от оси разряда к периферии температура газа уменьшается и на расстоянии более половины радиуса рабочей камеры близка к комнатной. Такой разряд мы называем свободным.

На боковой стенке рабочей камеры перпендикулярно оси разряда находится электроразрядная ударная труба диаметром $40 \mathrm{~mm}$ и длиной $700 \mathrm{~mm}$. Выходной торец ударной трубы расположен на расстоянии $100 \mathrm{~mm}$ от оси разряда. Скорость волны на выходе трубы доходит до $1.3 \mathrm{~km} / \mathrm{s}$, что соответствует числу Маха 3.8. Положение ударной волны регистрировалось при помощи оптической шлиренсистемы с погрешностью не более $3 \mathrm{~mm}$. Здесь и далее при вычислении значения числа Маха используется локальная температура нейтральной компоненты. Более подробно установка описана в [5].

При прохождении ударной волны через разряд измерялись интегральные электрические параметры газового разряда. На рис. 1 показано изменение тока и напряжения на электродах разрядного промежутка при прохождении ударной волны через разряд. Здесь и далее время отсчитывается от момента прихода ударной волны к оси разряда. На

Письма в ЖТФ, 2017, том 43, вып. 11 

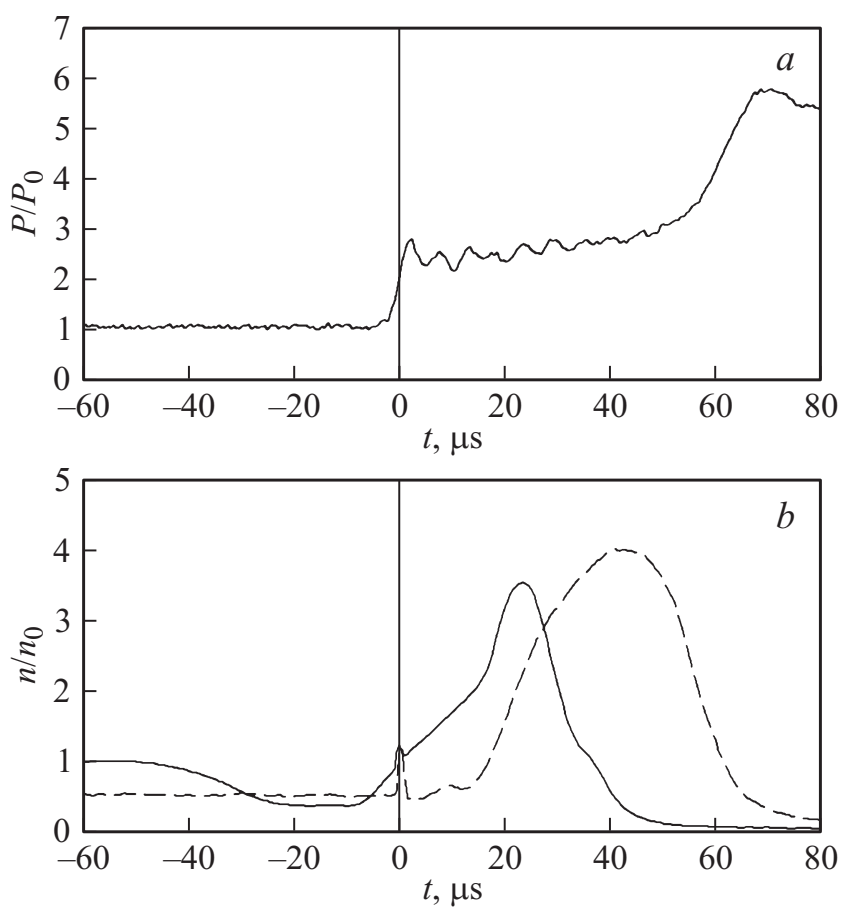

Рис. 2. Изменение полного давления $(a)$ и относительной концентрации ионов $(b)$ в неравновесной (сплошная линия) и равновесной (штриховая линия) плазме в центре разряда при прохождении ударной волны.

графиках видно, что изменение разрядного тока начинается тогда, когда ударная волна находится на расстоянии примерно $80 \mathrm{~mm}$ от оси разрядного промежутка, т.е. практически сразу по выходе из канала ударной трубы. К моменту прихода ударной волны к оси разряда ток уменьшается примерно на $20 \%$, а напряжение увеличивается на $10 \%$ от начального уровня, соответствующего режиму стационарного горения.

Особенность решаемой задачи состоит в том, что ударная волна движется по пространству с локальной тепловой неоднородностью. Число Маха ударной волны внутри неоднородности значительно меньше числа Маха вне нее. Оценки, сделанные по результатам измерения 
скорости ударной волны, показывают, что число Маха в центре разряда не превышает 1.3, а в его отсутствие составляет 3. Доказательством существования ударной волны в разряде является сигнал датчика полного давления, показанный на рис. 2,a. Измерения проводились пьезоэлектрическим датчиком, ориентированным навстречу ударной волне. В целях защиты от высокой температуры датчик располагался вне разряда. Динамическая нагрузка передавалась к датчику через кварцевый стержень длиной $0.5 \mathrm{~m}$. Один торец стержня соединен с чувствительным элементом датчика, другой - располагался в точке измерения (в данном случае на оси разряда). Величина полного давления нормирована на значение начального давления в рабочей камере. На рисунке видно, что до прихода ударной волны полное давление не меняется. Непосредственно за фронтом волны наблюдается ступенчатое увеличение полного давления в 1.5 раза и его постоянство в течение $40 \mu \mathrm{s}$, плотность газа при этом увеличивается примерно на $30 \%$. Наблюдаемое после $40 \mu$ s увеличение полного давления происходит за счет притока в точку измерения внешнего более плотного газа, т.е. после прихода ударной волны в центр разряда в течение примерно $40 \mu \mathrm{s}$ в этой точке существует нагретый разрядом газ, который потом вытесняется холодным. Динамика этого процесса изложена в [4].

Локальные параметры плазмы измерялись при помощи двойного электрического зонда, работающего в режиме насыщения ионного тока. Предварим обсуждение зондовых измерений небольшим пояснением. Ток двойного зонда в режиме насыщения ионного тока пропорционален произведению концентрации ионов и квадратному корню из электронной температуры. Предполагая, что температура электронов не меняется, можно считать, что ток зонда пропорционален концентрации ионов. Это допущение справедливо, поскольку к $40 \mu \mathrm{s}$ напряжение в разрядном промежутке - одна из причин изменения электронной температуры - увеличилось не более чем на 25\% (рис. 1).

На рис. 2, $b$ сплошной кривой показано относительное изменение концентрации ионов на оси разряда при движении по нему ударной волны. Величина концентрации отнесена к значению в стационарном разряде. Погрешность измерений относительной концентрации оценивается на уровне \pm 0.1 . На рисунке видно, что начальный уровень относительной концентрации начинает уменьшаться примерно за $50 \mu \mathrm{s}$ до прихода ударной волны в точку измерения и продолжается примерно $30 \mu \mathrm{s}$, после чего устанавливается уровень, соответствующий $1 / 3$ начального.

Письма в ЖТФ, 2017, том 43, вып. 11 
Начавшееся примерно за $7 \mu$ s до прихода к зонду ударной волны линейное увеличение относительной концентрации продолжается за ее фронтом до $15 \mu \mathrm{s}$. Далее виден резкий рост сигнала с последующим уменьшением до нуля. Примечательно, что момент времени $\sim 40 \mu \mathrm{s}$, когда концентрация ионов становится близкой к нулю, соответствует началу увеличения полного давления - притоку внешнего непроводящего газа.

Колебательный характер распределения ионов позволяет предположить, что движение ударной волны в плазме разряда приводит к возбуждению в ней ионно-звуковой волны, что характерно для неравновесной плазмы. Если предположение справедливо, то в равновесной плазме такого изменения плотности ионов не должно быть.

Для проверки сделанного предположения были проведены измерения в равновесной плазме. Экспериментальная установка позволяет также исследовать взаимодействие ударной волны с распадающейся плазмой, которая формируется при быстром снятии напряжения на электродах разрядного промежутка. В этом случае температура электронов уменьшается до температуры ионов за время меньше $1 \mu \mathrm{s}$. Эксперименты по взаимодействию ударной волны с распадающейся плазмой проводились через $0.7 \mathrm{~ms}$ после снятия напряжения на разрядном промежутке, что гарантировало равновесное состояние плазмы.

Изменение концентрации ионов в равновесной плазме, отнесенной к значению концентрации в стационарном разряде, показано на рис. $2, b$ штриховой линией. При пересчете величины зондового тока в значения относительной концентрации учитывалось примерно 10-кратное уменьшение температуры электронов в равновесной плазме относительно неравновесной. На рисунке видно, что начальная концентрация в этом случае вдвое меньше уровня в неравновесной плазме и ее величина практически не меняется до момента $15 \mu \mathrm{s}$. Это подтверждает предположение о том, что причиной уменьшения концентрации ионов перед ударной волной могут быть ионно-звуковые волны, возбуждаемые движением ударной волны в неравновесной плазме.

На обоих распределениях относительной концентрации момент прихода ударной волны в точку измерения отмечен характерным коротким „Всплеском“. Однако оба эти распределения относительной концентрации отличаются от ступенчатого изменения плотности нейтральной компоненты непосредственно за фронтом ударной волны.

Письма в ЖТФ, 2017, том 43, вып. 11 
Еще одна особенность распределения концентрации ионов как в неравновесной, так и в равновесной плазме заключается в наличии локального максимума в моменты времени 20 и $40 \mu$ s соответственно. Причина более чем 3-кратного увеличения концентрации по сравнению с уровнем в стационарном разряде неизвестна. Нет оснований связывать это изменение с газодинамическим процессом, поскольку максимум (сплошная линия на. рис. $2, b$ ) реализуется при практически неизменном уровне полного давления (рис. $2, a$ ).

В результате исследования показано, что эффект уменьшения концентрации ионов перед фронтом ударной волны, наблюдаемый только в неравновесной плазме, связан с возникновением в ней ионно-звуковых колебаний. Распределение плотности ионов в окрестности фронта ударной волны как в неравновесной, так и в равновесной плазме отличается от ступенчатого изменения плотности нейтральной компоненты.

\section{Список литературы}

[1] Чутов Ю.И. // ПМТФ. 1970. № 1. С. 124-130.

[2] Басаргин И.В., Мишин Г.И. // Письма в ЖТФ. 1985. Т. 11. В. 4. С. 209-215.

[3] Горшков В.А., Климов А.И., Коблов А.Н. и др. // ЖТФ. 1987. Т. 57. В. 10. C. 1893-1898.

[4] Барышников А.С., Басаргин И.В., Бобашев С.В. и др. // Письма в ЖТФ. 2015. T. 41. B. 15. C. 83-89.

[5] Барышников А.С., Басаргин И.В., Бобашев С.В. и др. // ИФЖ. 2016. Т. 89. № 3. C. 555-558.

Письма в ЖТФ, 2017, том 43, вып. 11 